\title{
ANALISIS PENGGUNAAN FASILITAS TARIK TUNAI SALDO GOPAY MELALUI ATM XXX DENGAN MEKANISME TARIK TUNAI TANPA KARTU DI JAKARTA
}

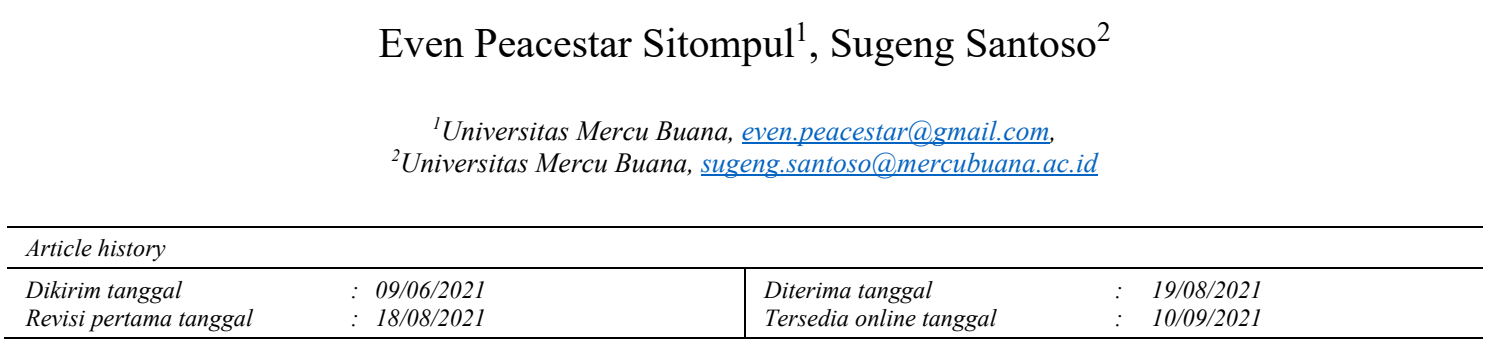

\begin{abstract}
The bank is a financial service provider whose primary choice is for the community's financial-related needs. However, with increased mobility and the people's need for ease financial transactions, various technology-based innovations have emerged to safely, comfortably, and quickly fulfill community activities. One of the methods of financial service that has become the choice of Indonesians is finance technology (fintech). Fintech is a merger of the financial system various aspects of financial services. Go-Pay is a fintech in Indonesia that is a mobile payment service on the Go-Jek platform. Go-Pay provides to provide convenience and comfort for the transaction process carried out in Go-Jek. For banks not to be less competitive with Fintech, there is a need for adjustments and cooperation to strengthen business potential. PT. $X X X(X X X)$ collaborates with Go-Pay in the Go-Pay cash withdrawal mechanism through XXX ATMs with the Cardless Cash Withdrawal mechanism as a form of banking synergy with fintech to facilitate transactions for Indonesians. This study purposes to determining how much the level of use of these facilities, especially in the community in Jakarta
\end{abstract}

Keywords: Consumer Behavior, Financial Technology (Fintech), Information Technology

\begin{abstract}
ABSTRAK
Perbankan merupakan penyedia jasa layanan keuangan yang menjadi pilihan utama masyarakan dalam pemenuhan kebutuhan yang berhubungan dengan finansial. Namun dengan meningkatnya mobilitas serta kebutuhan masyarakat terhadap kemudahan transaksi finansial, maka timbul beragam inovasi berbasis teknologi yang bertujuan untuk memenuhi aktivitas masyarakat dengan aman, nyaman dan cepat. Salah satu metode layanan jasa keuangan yang menjadi pilihan masyarakat Indonesia adalah financial technology (fintech). Fintech merupakan penggabungan sistem keuangan dengan teknologi dengan tujuan mempertajam, mengubah, dan mempercepat berbagai aspek pelayanan keuangan. Go-Pay adalah salah satu fintech di Indonesia yang merupakan layanan mobile payment yang terdapat pada platform Go-Jek. Go-Pay disediakan untuk memberikan kemudahan dan kenyamanan bagi proses transaksi yang dilakukan dalam Go-Jek. Agar perbankan tidak kalah bersaing dengan Fintech, maka perlu adanya penyesuaian serta kerja sama dengan tujuan saling memperkuat potensi bisnis. PT. XXX (XXX) melakukan kolaborasi bersama Go-Pay dalam mekanisme tarik tunai Go-Pay melalui mesin ATM XXX dengan mekanisme Tarik Tunai Tanpa Kartu sebagai bentuk sinergi perbankan dengan fintech agar dapat memudahkan transaksi masyarakat Indonesia. Tujuan penelitian ini adalah untuk mengetahui seberapa besar tingkat penggunaan fasilitas tersebut khususnya pada masyarakat di Jakarta
\end{abstract}

Kata Kunci: Perilaku Konsumen, Finansial Teknologi, Teknologi Informasi 


\section{PENDAHULUAN}

Indonesia sedang memasuki era globalisasi dan digitalisasi. Kegiatan yang dilakukan masyarakat Indonesia tidak jauh dari unsur teknologi dan unsur digital. Lajunya perpindahan informasi dan data yang sangat cepat, hingga perilaku dari masyarakat perlahan mulai berubah seiring dengan perkembangan teknologi. Kegiatan mulai dari keseharian, pendidikan, hingga bisnis kini berubah. Tranksaksi global pun berjalan seakan tidak ada sekat perbedaan negara dan geografi yang kemudian mendorong banyak pihak melakukan inovasi dalam proses transaksi keuangan. Inovasi diartikan sebagai suatu gagasan baru yang diterapkan untuk memprakarsai atau memperbaiki sebuah produk atau proses dan jasa. Inovasi merupakan bentuk penerimaan oleh pengguna dan masyarakat dari keberhasilan invensi, implementasi teknologi dan riset serta pengembangan. Salah satu bentuk untuk mentransformasikan perubahan nilai tersebut adalah dengan melakukan komersialisasi. Dalam pelaksanaan riil, proses transformasi tersebut tidak mudah dan tergolong kompleks karena perjalanan proses invensi suatu produk akan menghadapi sejumlah tantangan besar. Meskipun dapat menjadi sebuah hambatan, tantangan tersebut harus dihadapi untuk mencapai tujuan transformasi invensi menjadi inovasi hingga produk berhasil diterima oleh pasar. (Sugeng Santoso et al, 2021).

Di dunia digital, inovasi muncul di lingkup lembaga keuangan, dengan tujuan mendorong pertumbuhan ekonomi secara arah yang lebih baik. Seiring berjalannya waktu, perkembangan ini mengubah keuangan industri ke era digital dengan memadukan teknologi dan keuangan yang kemudian disebut sebagai financial technology (Fintech). (Alika et al, 2021)

Fintech secara global menunjukkan secara pesat dan perkembangannya melalui berbagai sektor, mulai dari perusahaan startup pembayaran, pinjaman, perencanaan keuangan (personal finance), investasi ritel, pembiayaan, remitansi, riset keuangan, dan lain sebagainya. Pelaku fintech di Indonesia masih didominasi oleh sektor bisnis payment (43\%), pinjaman (17\%), dan sisanya berbentuk agregator, crowdfunding dan lain-lain (Rahma $\mathrm{S}$ et.al, 2021). E-commerce merupakan salah satu hasil inovasi dalam proses transaksi dan perdagangan di sektor personal finance. Perkembangan e-commerce di Indonesia pun terbilang cukup cepat, meskipun baru memasuki tahap perkenalan. Berbeda dengan Tiongkok, Indonesia masih tertinggal jauh jika dilihat dari perkembangan e-commercenamun tidak menutup kemungkinan bahwa Indonesia akan menjadi pemain ekonomi digital terbesar di Asia Tenggara. Hal ini didukung oleh bentuk negara Indonesia yang merupakan negara kepulauan, e-commerce sangat cocok bagi Indonesia. Selain itu, demografi di Indonesia yang saat ini mengalami peningkatan kelas menengah akan menjadi salah satu faktor e-commerce terus tumbuh. Kelas menengah dengan daya konsumsi yang tinggi akan meningkatkan performa ecommerce di Indonesia. Dikutip dari Media Indonesia, diprediksi jumlah masyarkat kelas menengah akan terus meningkat. Kini jumlah kelas menengah berjumlah 40 juta jiwa, dan akan naik 5 kali lipat di tahun 2020. Teknologi informasi telah dimanfaatkan untuk mengembangkan industri keuangan yang dapat mendorong tumbuhnya alternatif pembiayaan bagi masyarakat. Modal finansial bagi ekonomi kreatif yang berdaya saing diwakili oleh kriteria startup yang layak menggunakan modal ventura, antara lain: (1) Karakteristik Wirausahawan; (2) Karakteristik Produk/Layanan; (3) Karakteristik Pasar; (4) Karakteristik Keuangan (Hudson and Evans, 2005); (Santoso, 2020) 
Perubahan perilaku konsumen dan produsen tersebut juga berdampak pada munculnya banyak penyedia layanan jasa keuangan non bank berbasis teknologi atau biasa disebut financial technology (fintech). Di tengah berbagai inisiatif pengembangan jaringan elektronik dan produk \& layanan berbasis digital, perbankan harus dapat membangun kolaborasi dengan perusahaan-perusahaan yang bergerak di bidang e-commerce dan fintech, dimana inovasi dan pandangan ke depan memberikan peluang besar bagi industri perbankan. Dengan memperkuat kolaborasinya dengan perusahaan fintech dan e-commerce melalui teknologi, maka dapat terjadi seamless integration antara platform Bank dengan platform fintech dan $e$ commerce. Namun selain fokus kepada layanan digital, Bank tetap menyadari pentingnya peran kantor cabang dalam melayani nasabah yang memiliki kebutuhan-kebutuhan yang tidak dapat dilayani oleh layanan digital atau mereka yang memang lebih menyukai layanan yang bersifat personal.

Kemudahan dalam mobile payment sendiri akan terasa manfaatnya bagi penduduk yang angka transaksi online-nya terus meningkat. Menurut penelitian yang dilakukan oleh Bothun, terdapat beberapa keuntungan yang membuat masyarakat memilih untuk menggunakan mobile payment. Keuntungan yang pertama adalah dapat lebih berhemat. Perusahaan biasanya memberikan promosi terhadap pengguna dompet digital mereka dengan kupon atau diskon dari jasa yang mereka tawarkan. Responden dari penelitian Bothun beranggapan dengan banyaknya diskon dapat menghemat pengeluaran mereka. Keuntungan berikutnya adalah kemudahan dalam transaksi dan keseharian. User tidak perlu membawa dompet untuk melakukan transaksi, cukup dengan smartphone dan jaringan internet mereka bisa bertransaksi, maka dari itu adanya mobile payment ini dapat mempermudah proses transaksi. Bagaimanapun kemudahan dalam transaksi merupakan daya tarik tersendiri bagi user atau pelanggan.

XXX mengacu pada kualitas pengembangan produk. Kualitas dari sebuah produk memiliki manfaat dalam perspektif pemasaran karena kualitas produk bisa menjadi prototipe untuk positioning dan diferensiasi produk perusahaan (Hajjat \& F. Hajjat: 2014). Positioning adalah posisi perusahaan diantara produk-produk lainnya di pasar, sedangkan diferensiasi adalah pembeda dari produk perusahaan dibandingkan dengan produk perusahaan yang lain.

\section{KAJIAN PUSTAKA}

\section{Perilaku Konsumen}

Konsumen adalah seseorang yang menggunakan atau memakai produk atau jasa yang disediakan (Fadila and D. Ridho: 2013). Konsumen adalah individu yang membeli produk atau jasa untuk dirinya. Konsumen adalah seseorang pengambil keputusan yang mana mempunyai kuasa penuh atas keputusan membeli atau tidak membeli barang atau jasa. Menurut P. Kotler and K. L. Keller (2015), konsumen adalah individu yang membeli dari orang lain.

Jadi yang disebut konsumen adalah orang yang memegang kendali atas keputusan pada suatu pembelian dan menggunakan produk yang ia beli. Perilaku konsumen adalah serangkaian proses yang dijalani oleh individu dalam mencari, membeli, menggunakan, mengevaluasi dan bertindak pasca penggunaan produk ataupun jasa dalam pemenuhan kebutuhannya (Ristiyanti: 2004). Menurut Kotler perilaku konsumen merupakan studi mengenai seseorang, kelompok atau organisasi memilih, membeli, menggunakan, suatu barang, jasa, atau pengalaman untuk memenuhi kebutuhan dan memuaskan diri mereka. 
Sejalan dengan perkembangan dunia usaha informasi dan komunikasi yang semakin pesat yang didukung oleh semakin canggihnya teknologi, maka semakin pesat pula persaingan di antara pengusaha komunikasi dan informasi untuk menarik konsumen dan menguasai pangsa pasar yang ada. Selajutnya maka produsen harus dapat menghasilkan barang dan jasa yang sesuai dengan kebutuhan konsumen tersebut. pemahaman mengenai perilaku konsumen adalah pengetahuan yang sangat penting agar dapat memahami kebutuhan, keinginan dan harapan konsumen secara lebih baik (Peter: 2014). Dalam proses penciptaan barang dan jasa yang sesuai dengan kebutuhan konsumen, produsen harus memiliki standar Manajemen Mutu yang baik. Manajemen mutu didefinisikan sebagai salah satu bagian manajemen rantai pasok dalam fokusnya meningkatkan kepuasan pelanggan melalui kepatutan pada standar dan prosedur dan ketepatan pembuatan keputusan dalam melindungi hak konsumen di waktu yang sama dengan upayanya meminimalisir kerugian perusahaan (Putro dan Sugeng S, 2021). Pemahaman yang mendalam mengenai Manajemen Mutu akan mempengaruhi keputusan konsumen dalam menentukan pemilihan suatu produk, sehingga mau membeli apa yang ditawarkan pemasar. Perkembangan teknologi informasi dan komunikasi yang ada menyebabkan masyarakat menggunakan alat komunikasi yang dinilai mempunyai fungsi praktis dan cepat oleh karena itu sangat tidak mengherankan apabila di dalam realita masyarakat banyak dijumpai pengguna fintech dan e-commerce. Selain itu, perkembangan teknologi informasi dan komunikasi berdampak pada keberlangsungan pengembangan kualitas produk. Kualitas dari sebuah produk akan mempengaruhi nilai-nilai yang bisa diberikan kepada target market, dimana nilai-nilai tersebut memberikan keuntungan dan kepuasan. Tinggi rendahnya keuntungan yang didapatkan dan tinggi rendahnya kepuasan yang dirasakan konsumen menentukan terhadap tinggi rendahnya kualitas sebuah produk (Fitriana \& Soetjipto: 2015)

\section{Teknologi Informasi}

Dunia Teknologi Indonesia saat ini tidak lagi menjadi suatu hal yang asing bagi masyarakat Indonesia, karena Teknologi Informasi telah banyak membantu masyarakat Indonesia dalam menjalankan roda perekonomian menjadi lebih efektif dan efisien dari sebelumnya. Teknologi informasi telah digunakan untuk mengembangkan industri keuangan yang dapat mendorong pertumbuhan alternatif pembiayaan bagi masyarakat.(Sugeng Santoso, 2020)

Hal ini pula yang mendorong berbagai perusahaan di Indonesia untuk menggunakan Teknologi Informasi untuk mempermudah kegiatan mereka melalui komunikasi yang cepat ke seluruh Indonesia hingga dunia serta dianggap dapat menekan biaya operasional perusahaan. Menteri Riset, Teknologi, dan Pendidikan Tinggi Republik Indonesia, No. 42 Tahun 2016 tentang Pengukuran dan Penetapan Tingkat Kesiapterapan Teknologi, yang menyatakan bahwa: a). Bahwa untuk mengetahui kesiapterapan suatu Teknologi dan mengurangi risiko kegagalan dalam pemanfaatan teknologi, perlu dilakukan Pengukuran dan Penetapan Tingkat Kesiapterapan Teknologi; b). Teknologi adalah cara atau metode serta proses atau produk yang dihasilkan dari penerapan dan pemanfaatan berbagai disiplin ilmu pengetahuan yang menghasilkan nilai bagi pemenuhan kebutuhan, kelangsungan, dan peningkatan mutu kehidupan manusia; c). Tingkat Kesiapterapan Teknologi (Technology Readiness Level) yang selanjutnya disingkat dengan TKT adalah tingkat kondisi kematangan atau kesiapterapan suatu hasil Penelitian (research) dan pengembangan teknologi tertentu yang diukur secara sistematis dengan tujuan untuk dapat diadopsi oleh pengguna, baik oleh 
pemerintah, industri maupun masyarakat; d). TKT disusun dalam 9 (sembilan) tingkatan yang masing-masing tingkatan memiliki indikator capaian TKT (KH Solaiman et al, 2021). Dalam lingkup keuangan, peranan teknologi informasi berbasis internet memiliki potensi secara mendasar untuk mengubah bank dan industri perbankan dalam berspekulasi, bahwa internet akan menghancurkan model lama tentang bagaimana layanan perbankan dikembangkan dan disampaikan dengan pandangan secara ekstrim (DeYoung: 2001). Internet telah mengubah dimensi persaingan di sektor perbankan, setelah pengenalan ATM dan phone banking yang merupakan landasan awal keuangan elektronik, peningkatan adopsi internet telah menambahkan saluran distribusi baru dalam sektor perbankan yaitu Internet Banking (Onay: 2008).

Menurut penelitian yang dilakukan oleh Malhotra \& Singh (2009) di Spanyol, penggunaan internet banking memiliki dampak positif terhadap profitabilitas. Profitabilitas ini diukur dengan adanya pengurangan biaya overhead secara signifikan. Selain itu dengan penggunaan Internet Banking berdampak pada penurunan biaya staff, IT dan Marketing. Hal tersebut menjadi salah satu indikator semakin efisiennya bank-bank tersebut. Sedangkan bagi nasabah, penggunaan internet banking dapat mendorong efisiensi dalam proses transaksi. Bila pihak penyedia jasa keuangan dapat menyinergikan hadirnya fintech, maka layanan internet banking semakin meningkatkan pelayanan terhadap nasabah. Oleh karena itu diharapkan alur proses yang dibuat penyedia jasa keuangan dengan penggunaan sistem teknologi informasi dapat meningkatkan efisiensi serta mengurangi keluhan nasabah (Vinisia \& Sugeng S, 2021).Peningkatan layanan tersebut dapat disediakan oleh penyedia jasa keuangan yang memiliki kantor fisik dengan menciptakan sebuah situs web dan menyediakan layanan melalui bank virtual juga (Allen, 2002)

\section{Finansial Teknologi}

Sebagai salah satu bentuk penerapan teknologi informasi di bidang keuangan, fintech memiliki fungsi beragam, yang diyakini mampu dengan cepat berkembang secara cepat. Saat ini fintech mampu melayani electronic money, virtual account, aggregator, lending, crowdfunding dan transaksi keuangan online lainnya. Sedangkan dalam lingkup manajerial operasional secara luas, fintech merupakan sarana pendukung Supply Chain Mangement perusahaan. Penerapan konsep SCM dalam perusahaan akan memberikan manfaat yaitu kepuasan pelanggan, meningkatkan pendapatan, menurunnya biaya, pemanfaatan asset yang semakin tinggi, peningkatan laba, dan perusahaan semakin besar. (Sugeng Santoso et al, 2020). Adapun fintech yang telah beroperasi, sebagian ada yang didirikan oleh perusahaan berbasis konvensional, tetapi tidak sedikit pula yang merupakan perusahaan rintisan atau startup. Namun perkembangan fintech di Indonesia tetap berada dalam pengawasan Bank Indonesia (BI) selaku bank sentral. Inovasi yang berkembang di sini adalah pengadaptasian prinsip jaringan komputer yang diterapkan pada bidang keuangan. Fintech berasal dari istilah financial technology atau teknologi finansial. Menurut The National Digital Research Centre (NDRC), di Dublin, Irlandia, mendefinisikan fintech sebagai "innovation infinancial services" atau "inovasi dalam layanan keuangan fintech" yang merupakan suatu inovasi pada sektor finansial yang mendapat sentuhan teknologi modern. Teknologi keuangan berawal dari sektor keuangan dalam perekonomian yang menjadi sektor kunci dan terus berkembang sesuai dengan kebutuhan masyarakat (Carney: 2016). Teknologi keuangan tidak hanya diterapkan di negara maju saja, tetapi juga mulai muncul dan tumbuh di negara berkembang, seperti Indonesia. Financial technology membawa harapan baru bagi kemudahan dalam 
berbagai macam transaksi keuangan dalam berbagai sektor. Transaksi keuangan melalui fintech ini meliputi pembayaran, investasi, peminjaman uang, transfer, rencana keuangan dan pembanding produk keuangan.

Hadirnya internet dalam transaksi keuangan dapat memberikan keunggulan aksesbilitas dan jangkauan akses (Meifang: 2017). Salah satu contoh inovasi dalam bidang teknologi pembayaran keuangan adalah e-commerce. Beberapa faktor yang menunjang pertumbuhan peningkatan pertumbuhan e-commerce adalah pengaplikasian IOT dan cloud computing dalam sebuah rantai produksi, logistik, dan transportasi. Industri financial technologi (fintech) merupakan salah satu metode layanan jasa keuangan yang tumbuh sejalan dengan perkembangan internet dan pembayaran digital menjadi salah satu sektor dalam industri fintech yang paling berkembang di Indonesia. Sektor inilah yang kemudian paling diharapkan oleh pemerintah dan masyarakat untuk mendorong peningkatan jumlah masyarakat yang memiliki akses kepada layanan keuangan salah satunya adalah e-money Gopay. Go-Pay merupakan salah satu contoh financial technology di bidang sistem pembayaran. Go-Pay merupakan salah satu alternatif untuk melakukan transaksi pada aplikasi Go-Jek. Penggunaan Go-Pay memberikan kepraktisan, kemudahan, kenyamanan, serta memberikan keuntungan dalam transaksi pada aplikasi Go-Jek

\section{METODOLOGI PENELITIAN}

\section{Metode Pengumpulan Data}

Permasalahan yang dikaji dalam analisis ini adalah terkait penggunaan fasilitas tarik tunai tanpa kartu dengan sumber dana Gopay. Analisis menggunakan data primer yang bersifat original dan didapat melalui kuisioner yang dilakukan oleh peneliti sehingga dapat berfungsi untuk menyelesaikan masalah penelitian. Pengumpulan data kuesioner dan teknik sampling yang akan digunakan pada penelitian ini adalah nonprobabilitas sampling yang berarti pemilihan responden berdasar pada judgement dari peneliti sendiri. Metode sampling yang digunakan adalah convenience. Metode sampling convenience dipilih atas dasar keterbatasan kemampuan dari peneliti. Kriteria sampel pada penelitian ini adalah pengguna GO-PAY dan pengguna Mobile Banking XXX. Data yang diperoleh berjumlah 137 dengan responden.

\section{Jenis Data}

Data primer merupakan data yang bersifat original dari peneliti itu sendiri yang berfungsi untuk menyelesaikan masalah penelitian. Data ini akan didapat melalui kuisioner yang akan dijelaskan pada sub bab berikut. Pengumpulan Data Teknik pengumpulan data yang digunakan pada penelitian ini adalah kuesioner. Penelitian ini menggunakan kuesioner yang digunakan untuk mengumpulkan data terkait variabel-variabel yang nantinya akan diolah. Teknik sampling yang akan digunakan pada penelitian ini adalah nonprobabilitas sampling yang brarti pemilihan responden berdasar pada judgement dari peneliti sendiri. Metode sampling yang digunakan adalah convenience. Metode sampling convenience dipilih atas dasar keterbatasan kemampuan dari peneliti. Kriteria sampel pada penelitian ini adalah pengguna GO-PAY. 
HASIL DAN PEMBAHASAN

Gambaran Umum Responden

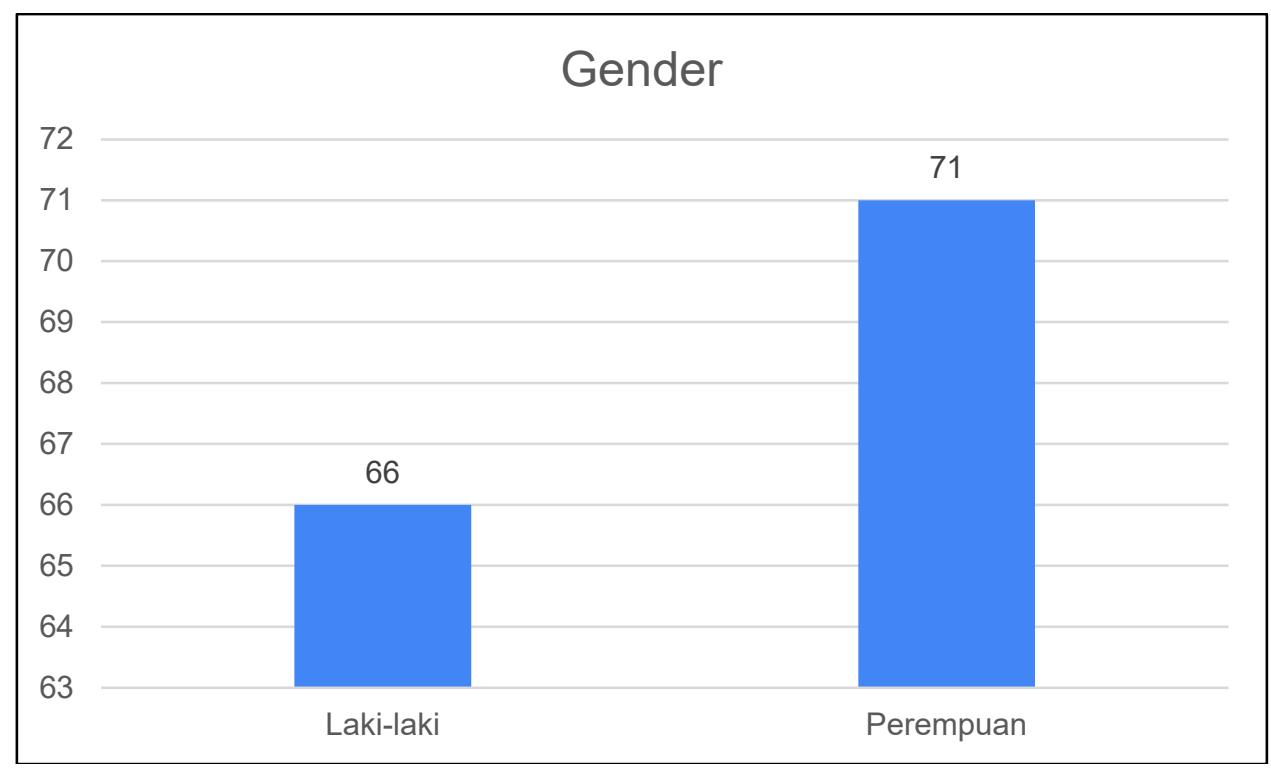

Gambar 1. Gender

Mayoritas responden dalam penelitian ini adalah perempuan dengan jumlah sebanyak 71 orang sedangkan laki-laki berjumlah sebesar 66 orang (Gambar 1).

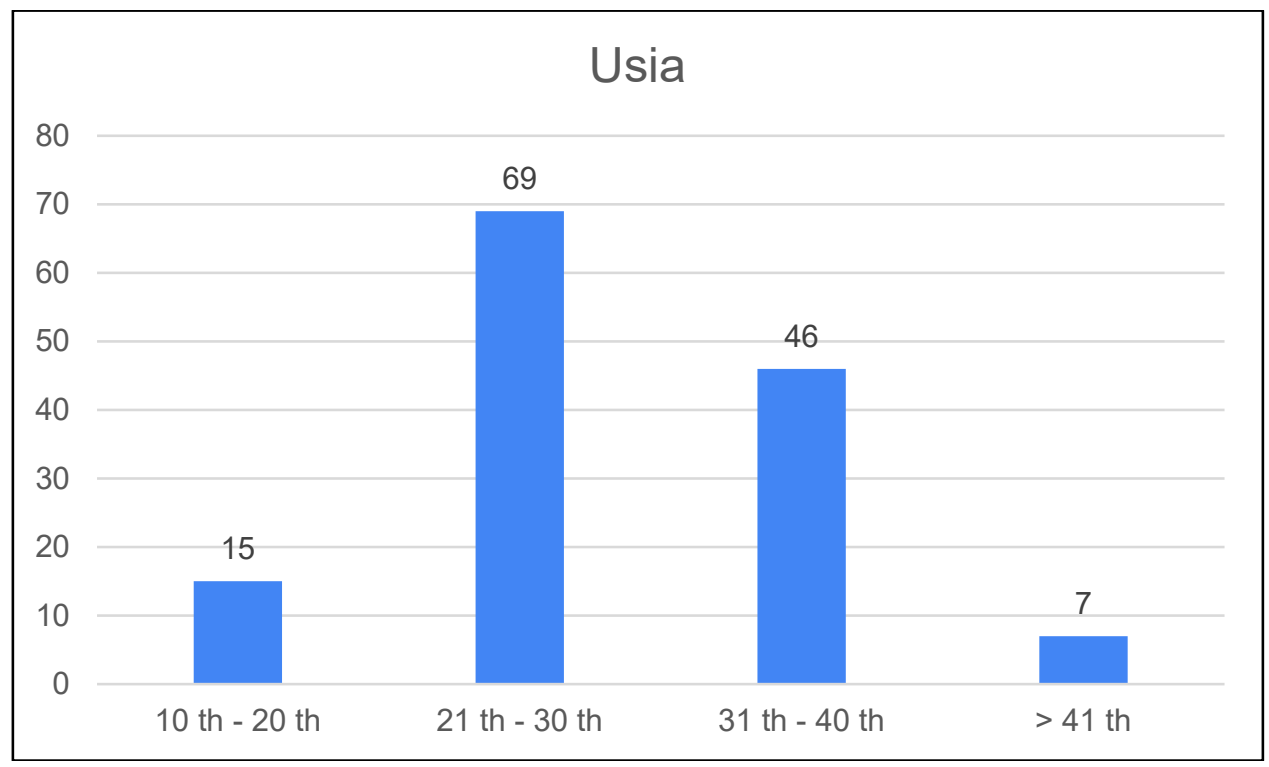

Gambar 2. Usia

Usia 21 - 30 tahun mendominasi jumlah responden dengan total jumlah 69 orang dan rentang usia $>41$ tahun menjadi responden paling sedikit yaitu sebanyak 7 orang (Gambar 2). 
Berdasarkan hasil di atas, penulis mengelompokan rentang usia menjadi 2 kelompok yaitu generasi $\mathrm{x}$, generasi y dan generasi $\mathrm{Z}$.

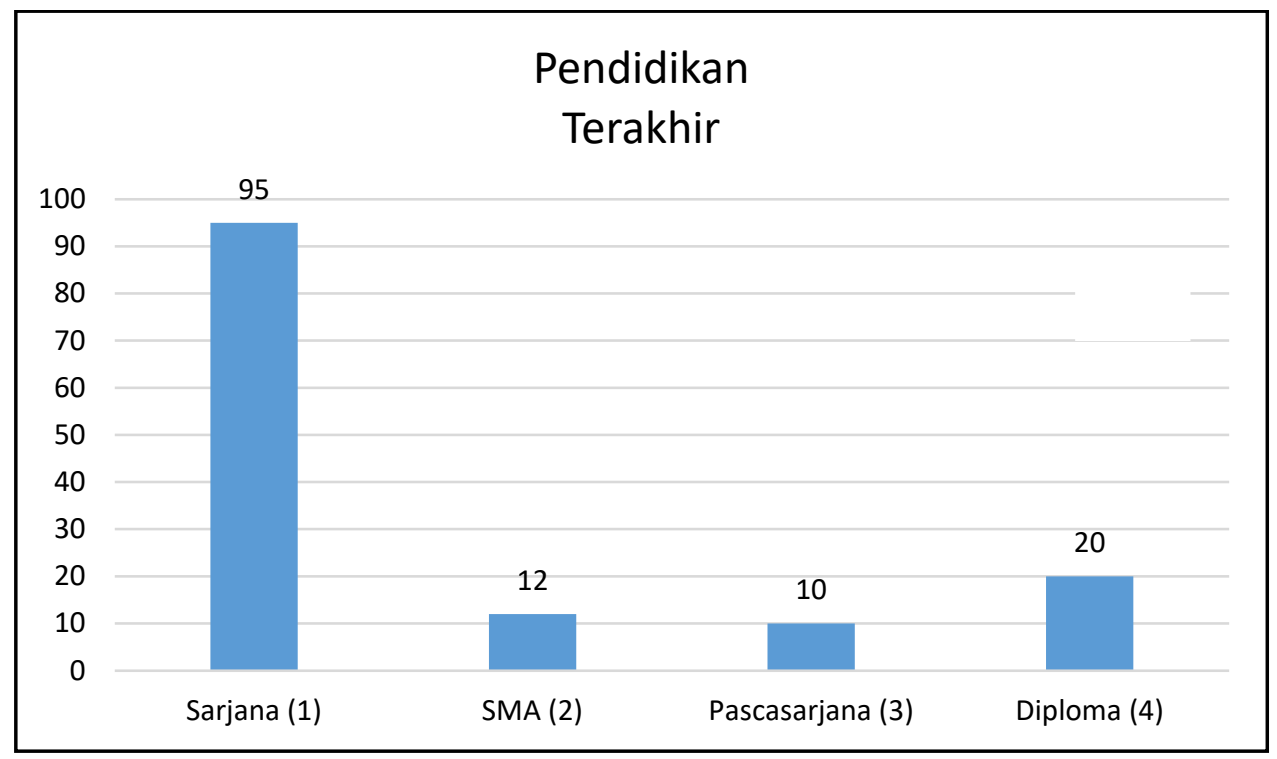

Gambar 3. Pendidikan Terakhir

Pendidikan terakhir yang paling banyak adalah Sarjana. Sebanyak 95 orang dari total responden mempunyai tingkat pendidikan Sarjana (Gambar 3). Lalu diikuti oleh Diploma sebanyak 20 orang, dan yang paling sedikit adalah pendidikan Pascasarjana dengan angka 10 orang

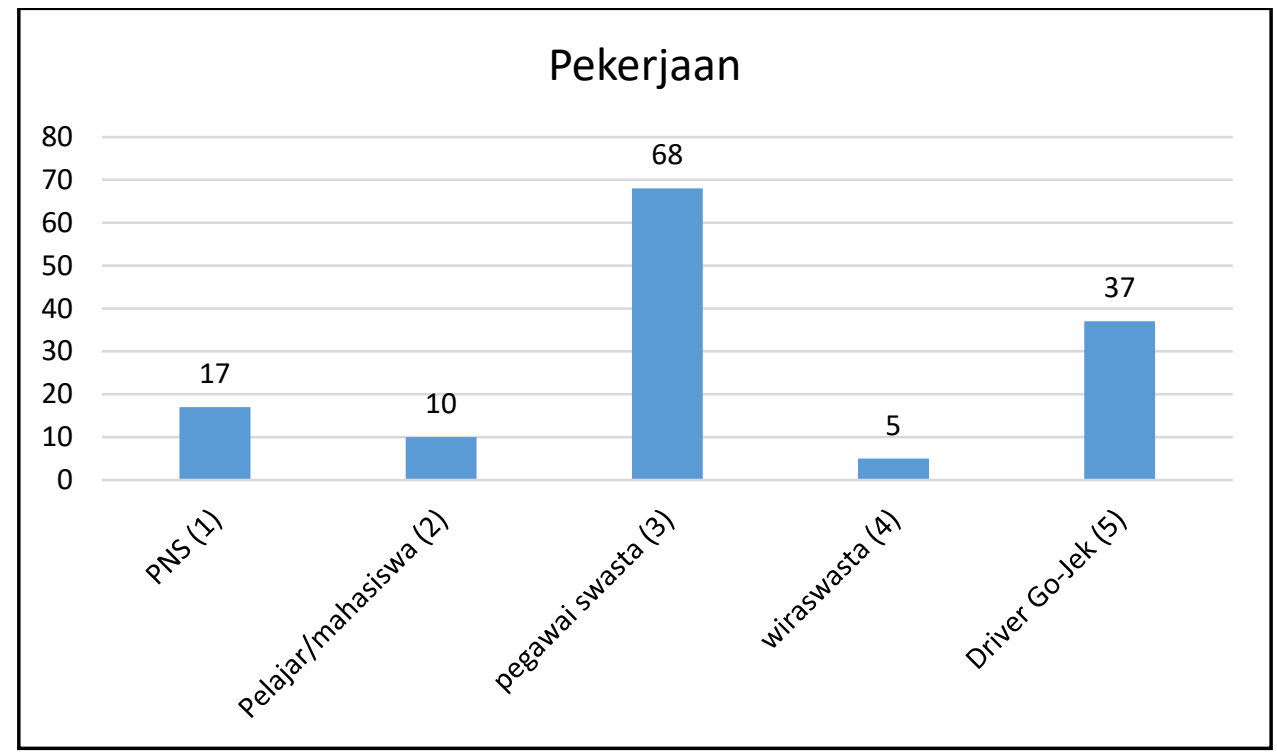

Gambar 4. Pekerjaan

Responden dari penelitian ini didominasi oleh Pegawai Swasta (Gambar 4) dengan angka mencapai 68 orang dari total responden. Ini bisa terjadi karena penyebaran kuesioner banyak dilakukan melalui relasi di lingkungan kerja penulis yang merupakan pegawai swasta. 
Selanjutnya responden terbanyak adalah Driver Go-Jek sebanyak 37 orang. Fakta tersebut terjadi karena peneliti juga menyebarkan kuesioner kepada kalangan driver khususnya GoJek. Untuk angka terkecil diperoleh dari responden dengan pekerjaan wiraswasta sebanyak 5 orang

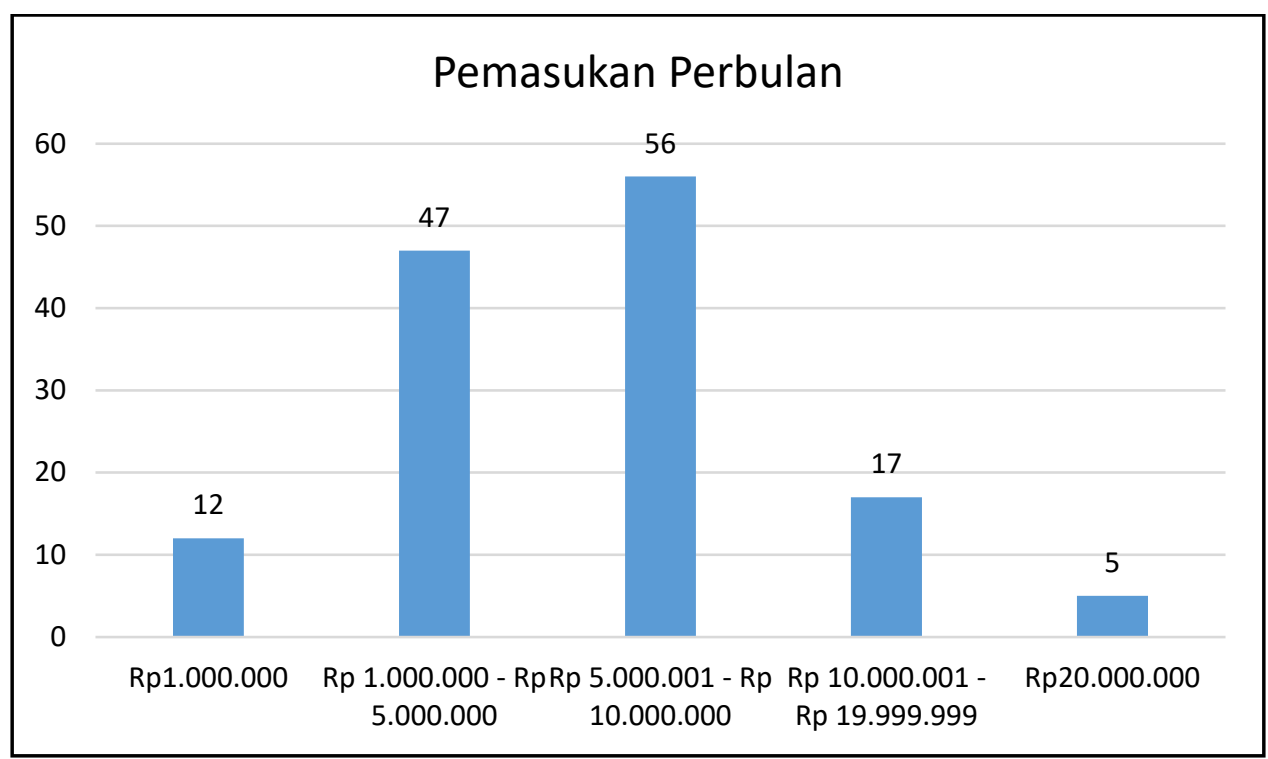

Gambar 5. Pemasukan Perbulan Responden

Pemasukan responden paling banyak dengan jumlah 56 orang masuk ke dalam rentang Rp 5.000.001 - Rp 10.000.000. Hal ini diduga karena sebagian besar responen merupakan pegawai swasta. Sedangkan responden dengan pemasukan dalam dibawah Rp 1.000.000 sebanyak 12 orang (Gambar 5). Ini diduga adalah responden yang merupakan pelajar dengan keadaan masih belum punya pemasukan sendiri. Selanjutnya pemasukan dengan rentang di atas Rp 20.000.000 berjumlah 5 orang

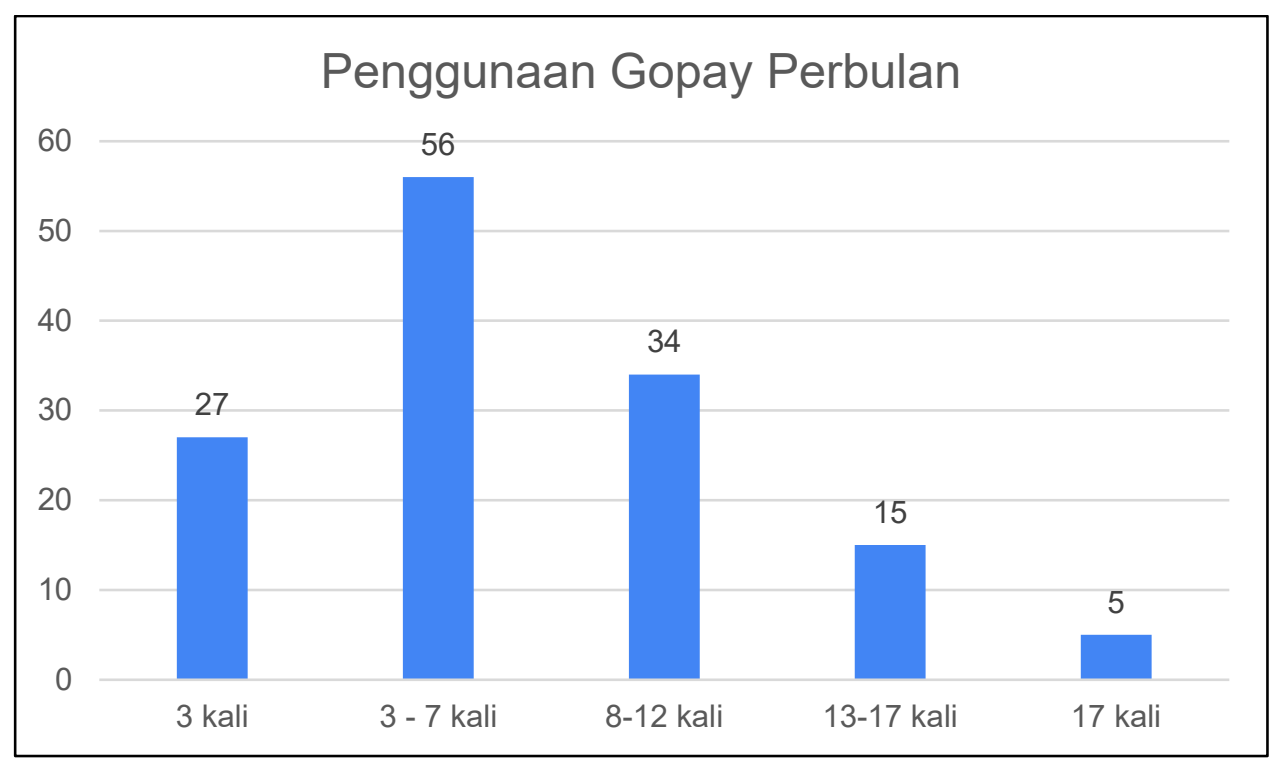

Gambar 6. Frekuensi penggunaan Go-Pay perbulan 
Sebagian besar responden menggunakan jasa GO-PAY sebanyak 3-7 kali dalam sebulan. (Gambar 6) dan kemudian diikuti dengan frekuensi penggunaan dalam rentang 8-12 kali dalam sebulan. Pengguna GO-PAY lebih dari 17 kali dalam sebulan merupakan jumlah paling sedikit yaitu sebanyak 5 orang.

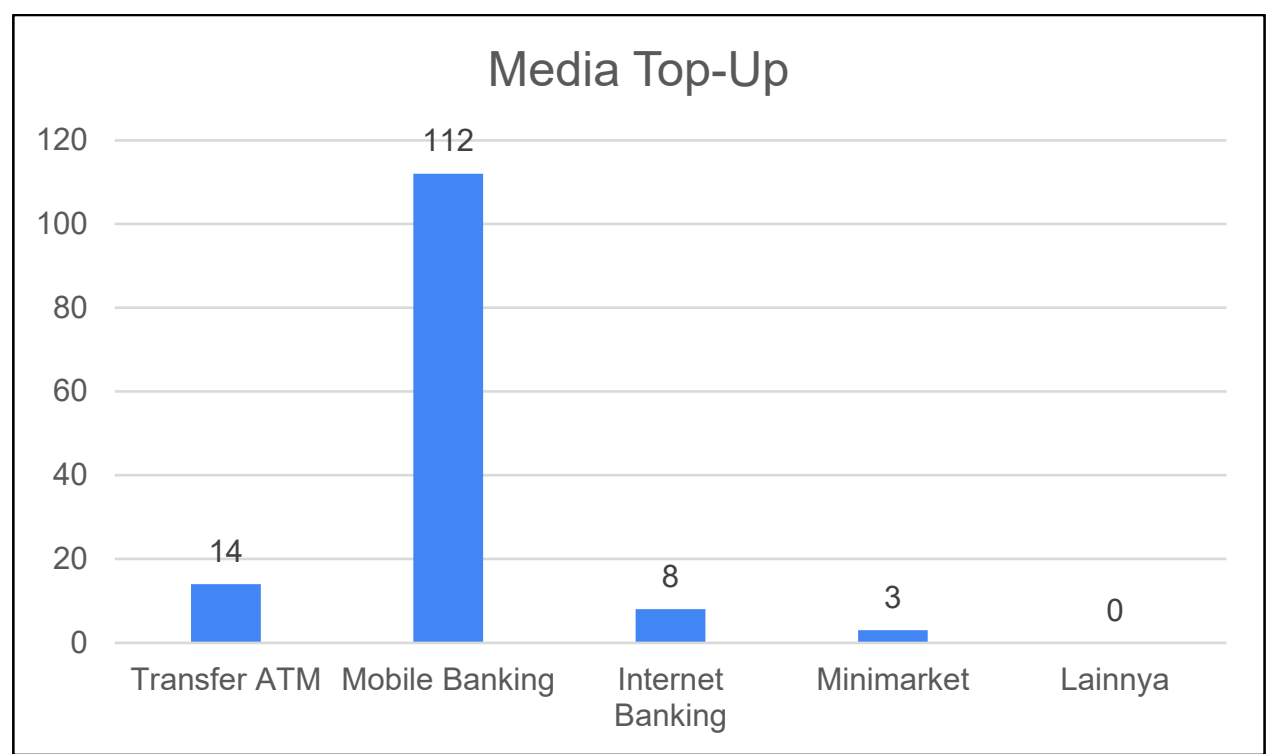

Gambar 7. Media Top-Up

Pengisian saldo GO-PAY cenderung menggunakan 2 media pengisian, yakni via Mobile Banking dan Via ATM. Media yang paling sering digunakan adalah melalui Mobile Banking dengan jumlah sebesar 112 orang (Gambar 9). Selanjutnya sebanyak 14 orang melakukan top-up melalui ATM. Untuk channel Internet Banking masih digunakan oleh 8 orang dan sisanya melalui minimarket.

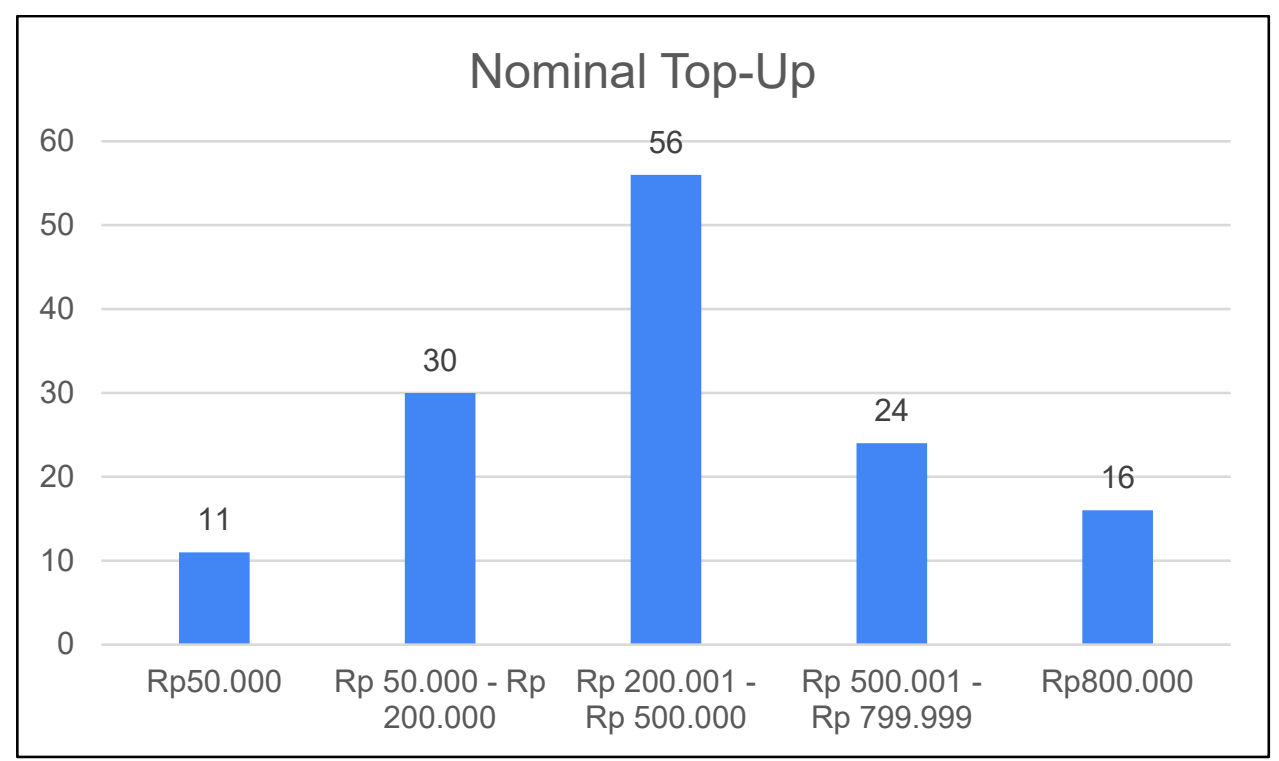

Gambar 8. Nominal Top-Up 
Responden cenderung melakukan top-up GO-PAY dengan rentang sebesar Rp 200.001500.000. Ini terbukti dengan banyaknya responden yang memilih sebanyak 56 orang dari total responden (Gambar 8). Sedangkan untuk top-up diatas 800.000 dilakukan oleh 16 responden. Hal tersebut disebabkan karena mobilitas responden yang sering menggunakan Go-Ride/Go-Car maupun memesan makanan melalui Go-Food sehingga melakukan top-up dengan jumlah banyak tiap awal bulan.

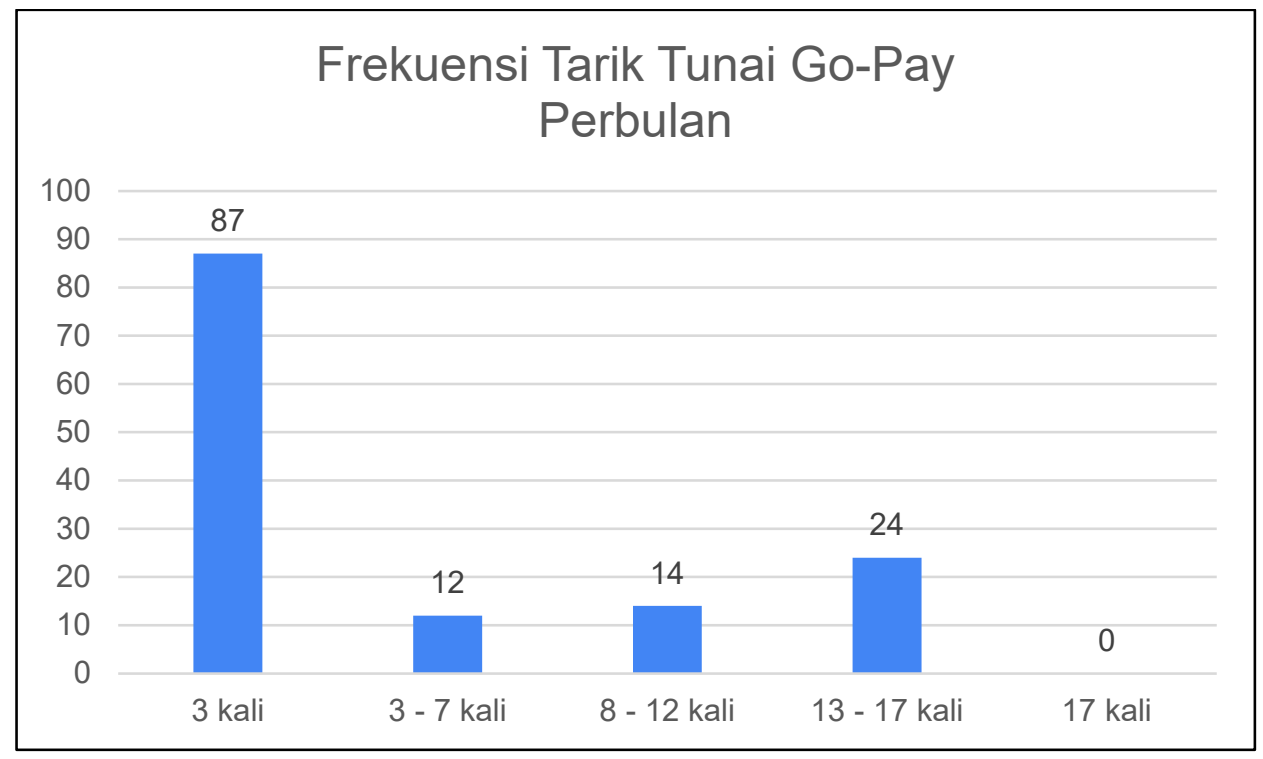

Gambar 9. Frekuensi Tarik Tunai Go-Pay Perbulan

Perilaku tarik tunai Go-Pay responden paling banyak dilakukan kurang dari 3 kali dalam satu bulan dengan jumlah 87 orang. Hasil paling banyak berikutnya merupakan frekuensi 13-17 kali dengan jumlah 24 orang. Bila mengacu pada data kuesioner, responden yang melakukan penarikan kurang dari 3 kali merupakan pegawai swasta dan PNS sedangkan frekuensi 1317 kali dilakukan oleh driver Go-Jek. Penarikan tunai oleh driver Go-Jek dilakukan karena tingginya penerimaan pembayaran jasa antar melalui Go-Pay, sehingga untuk mencairkan uangnya driver melakukan tarik tunai tanpa kartu di ATM XXX 


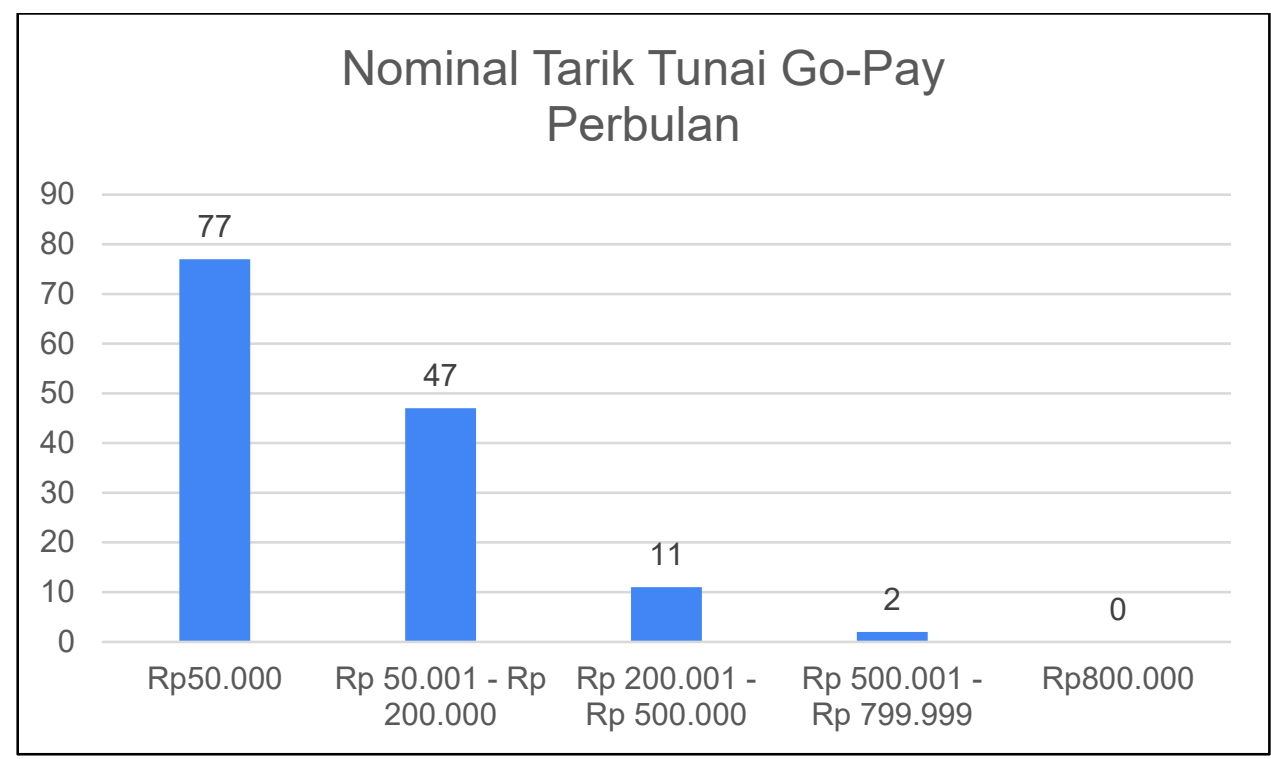

Gambar 10. Nominal Tarik Tunai Go-Pay Perbulan

Sebanyak 77 responden melakukan tarik tunai perbulan dengan nominal $\mathrm{Rp} 50.000$ dan nominal yang paling besar dilakukan penarikan oleh 2 responden. Untuk transaksi satuan, nominal Rp 50.000 merupakan nominal terkecil yang dapat diambil dari mesin ATM XXX dan nominal yang dapat ditarik paling besar adalah Rp 1.200.000. Penarikan Rp 50.000 paling banyak dilakukan oleh pegawai swasta dan nominal penarikan Rp 500.001 - Rp 800.000 dilakukan oleh wiraswasta

\section{Analisis Statistik Deskriptif}

Statistik deskriptif memberikan gambaran atau deskripsi suatu data yang dapat dilihat dari nilai rata-rata (mean), standar deviasi, maksimum, minimum, dari masing-masing variabel (Ghozali, 2011), $\mathrm{N}=$ jumlah responden.

Tabel 1.

Nominal Tarik Tunai Go-Pay Perbulan

\begin{tabular}{lccccr}
\hline \multicolumn{1}{c}{ Variabel } & N & Mean & $\begin{array}{c}\text { Standar } \\
\text { Deviation }\end{array}$ & Minimum & Maximum \\
\hline $\begin{array}{l}\text { Penggunaan GoPay } \\
\text { Perbulan }\end{array}$ & 137 & 6,3 & 0,36 & 3 & 17 \\
$\begin{array}{l}\text { Frekuensi Tarik Tunai Go- } \\
\text { Pay di Mesin ATM XXX }\end{array}$ & 137 & 7,4 & 0,58 & 3 & 17 \\
$\begin{array}{l}\text { Perbulan } \\
\text { Pekerjaan }\end{array}$ & 137 & 5,6 & 0,52 & 1 & 5 \\
\hline
\end{tabular}


Berdasarkan hasil analisis data pada tabel 1, penggunaan Go-Pay para responden dan Frekuensi Tarik Tunai Go-Pay di Mesin ATM XXX memiliki nilai minimum dan maksimum yang sama, dengan angka minimum 3 dan maksimum sebesar 17. Sedangkan rata-rata Penggunaan Go-Pay sebesar 6,3 kali setiap bulannya dan rata-rata Frekuensi Tarik Tunai GoPay di Mesin ATM XXX dari data tersebut adalah 7,4 kali setiap bulan. Kesimpulan dari data tersebut adalah responden jarang menggunakan fasilitas Go-Pay dan melakukan tarik tunai Go-Pay di mesin ATM XXX dalam kehidupan sehari-hari. Sedangkan pekerjaan para responden memiliki nilai minimum 1 dan maksimum 5 dengan nilai mean sebesar 5.6 yang artinya penggunaan Go-Pay dan frekuensi tarik tunai Go-Pay perbulan didominasi oleh kelompok Driver Gojek.

\section{KESIMPULAN DAN SARAN}

\section{Kesimpulan}

Berdasarkan data hasil penelitian mengenai analisis penggunaan fasilitas tarik tunai saldo Go-Pay melalui ATM XXX dengan mekanisme tarik tunai tanpa kartu di Jakarta yang telah dianalisis menggunakan Analisis Statistik Deskriptif, maka dapat disimpulkan sebagai berikut:

1. Kolaborasi antara Go-Jek dan XXX dalam penerapan fasilitas tarik tunai di mesin ATM XXX dengan mekanisme tarik tunai tanpa kartu menciptakan perilaku yang baru terhadap penggunaan fasilitas tersebut. Berdasarkan analisis deskriptif yang telah dilakukan menunjukkan bahwa pengguna tarik tunai Go-Pay lebih banyak perempuan. Hal ini terjadi mungkin karena perputaran Go-Pay perempuan lebih banyak daripada laki-laki seperti contohnya melakukan perjalanan dengan Go-Ride, sedangkan laki-laki cenderung memilih opsi transportasi lain. Kelompok usia mayoritas dalam penelitian ini berada pada generasi Y karena generasi tersebut sudah biasa menggunakan teknologi serta memiliki beragam kebutuhan yang dapat dipenuhi oleh aplikasi Go-Jek. Sedangkan mayoritas responden memiliki pendidikan terakhir sarjana, pekerjaan pegawai swasta dan penghasilan perbulan Rp 5.000.001 - 10.000.000. Bila dikaitkan dengan data kelompok umur, dapat disimpulkan bahwa mayoritas pengguna fasilitas Go-Pay adalah kelompok pekerja lulusan sarjana dengan rentang usia dewasa serta penghasilan di atas UMR Jakarta tahun 2021.

2. Mengacu pada analis variabel besaran frekuensi tarik tunai Go-Pay dan variabel besaran nominal penarikannya dan variabel pekerjaan didapat bahwa frekuensi tarik tunai GoPay tertinggi dilakukan oleh driver Go-Jek. Alasannya tentu karena perputaran Go-Pay driver Go-Jek memiliki perputaran yang tinggi baik penerimaan dari customer maupun pengeluaran untuk pembelian makanan/barang (Go-Food maupun Go-Shop) dan juga tarik tunai untuk kebutuhan uang cash. Sedangkan untuk nominal tarik tunai Go-Pay tertinggi berdasarkan data adalah sebesar Rp 500.000 - Rp 800.000 perbulan yang 
dilakukan campuran antara driver Go-Jek dan juga wirausaha. Bagi para pelakui bisnis, saat ini pembayaran tagihan maupun biaya operasional dengan nominal kecil juga dapat menggunakan Go-Pay karena mekanisme pembuatan akun serta pencatatan laporan yang tidak sulit. Atas dasar itu beberapa wirausaha melakukan penarikan tunai dengan nominal besar.

\section{Saran}

Saran yang diberikan peneliti untuk Perbankan dan pelaku fintech adalah memiliki target market fasilitas tarik tunai dengan sumber dana e-money yang lebih luas tidak terfokus kepada kelas pekerja tetapi juga untuk skala perusahaan. Sedangkan saran untuk penelitian selanjutnya adalah melakukan penelitian penggunaan digital wallet dalam transaksi operasional perusahaan serta hubungannya dengan peningkatan penggunaan channel perbankan

\section{REFERENSI}

Allen, F; Mcandrews, J; and P. Strahan. (2002). E-Finance: An Introduction. Journal of Financial Services Research, 22:1/2 5-27.

Carney, M. (2016). Enabling the Fintech Transformation: Revolution, Restoration, or Reformation. BoE Speech.

DeYoung, R. (2001). The Financial Performance of Pure Play Internet Banks. Economic Perspectives. Vol. 25(1):60-75.

DeYoung, R. (2001). The Financial Progress of Pure Play Internet Banks. BIS paper no 7

Fadila and D. Ridho. (2013). Perilaku Konsumen. Palembang: Citrabooks

Fitriana \& Soetjipto, B. E. (2015). The Analysis of Factors Affecting Customer Loyalty at McDonald. IJABER 13(9), 6853-6871

Hajjat, M. M. \& Hajjat, F. (2014). The Effect of Product Quality on Business Performance in Some

Arab Companies. Journal of Emerging Trends in Economics and Management Sciences 5(5), 498508.

Hudson and Evans. (2005). The Journal of Economic and Social Policy. Vol.10, Article 3

J. Peter. (2014). Consumer Behavior and Marketing Strategy. Jakarta: Salemba Empat, 
Meifang, Y., He, D., \& Zheng Xianrong, X. X. (2018). Impact of Payment Technology Innovations on the Traditional Financial Industry: A Focus on China. Journal of Technological Forecasting and Social Change, 199-2017.

Malhotra, P. and Singh. (2009). The Impact of Internet Banking on Bank Performance and Risk: The Indian Experience" Eurasian Journal of Business and Economics. Vol 2 (4): 43-62.

Mardiyanto, Handono. (2009). Intisari Manajemen Keuangan. Jakarta. Grasindo Onay, Ceylan; Ozsoz, Emrr; Helvacioglu, Ash Debiz. (2008). The Impact of Internet Banking on Banks Profitability - The Case of Turkey". Oxford Business and Economics Program.

P. Kotler and K. L. Keller. (2015). Marketing Management. Harlow: Pearson Education

P. Ristiyanti. (2004). Perilaku Konsumen. Yogyakarta: Andi Offset.

Santoso, Sugeng (2020). Optimizing Access to Financial Capital of Creative Economy for Startups Towards Global Competitiveness, BECOSS (Business Economic, Communication, and Social Sciences), 2(2), 13-21. DOI: https://doi.org/10.21512/becossjournal.v2i2.6246.

Santoso, S.; Nurzaki, A.; Santoso, A.; Benawan, C.; Wahyudin, D. (2020). Kinerja PT. PLN Unit Induk Distribusi Jakarta Raya Dengan Supply Chain Operation Reference, Jurnal Distribusi, 8(2), 255-266. DOI: 10.29303/ distribusi.v8i2.136.

Santoso, S.; Natanael, A.; Fatmawati, A.A.; Griselda, A.; Khoirunnisa, J.; Simanjuntak, M.; Bagus, A. A. R. (2021). Analisis Pengembangan Platform Ekspor Sub Sektor Kuliner Tinjauan Dari Model Sistem Inovasi, Jurnal Distribusi, 9(1), 29-38. DOI: $10.29303 /$ distribusi.v9i1.151.

Alika, V. A.; Santoso, S.; Nurmaliki, S.; Anisa, N. (2021). Marketing Strategy Sharia Financial Institutions to Promote Sharia Fintech and Micro and Small Enterprises (MSES). Proceedings of the 1st MICOSS Mercu Buana International Conference on Social Sciences, MICOSS 2020, EAI. doi:10.4108/eai.28-9-2020.2307373.

Rahma Septi Anzelina, Sugeng Santoso, Luthfi Aulia Safari, Dimas Iskandar, Fery Erwanda. (2021). Pembiayaan Dan Manfaat Financial Technology (Fintech) Syariah Pada 212 Mart, Syi’ar Iqtishadi: Journal of Islamic Economics, Finance and Banking, 5(1), 6892. DOI: http://dx.doi.org/10.35448/jiec.v5i1.9889.

Putro, S, S; Santoso, S. (2021). Desain Konseptual Digitalisasi Manajemen Mutu Pada Industri FMCG, Jurnal Mix: Jurnal Ilmiah Manajemen, 11(2), 147-162. DOI:10.22441/mix.2021.v11i2.001. 
KH Solaiman; Redata, L.; Kezia, R.; Santoso, S. (2021). Analisis Korelasi Pendampingan Komunitas Terhadap Inovasi Pelaku Ekonomi Kreatif Dan Pemenuhan Kebutuhan Konsumen: Studi Kasus Pada Komunitas Tangerang Berdaya Dan Pelaku Ekonomi Kreatif Kuliner Tangerang. Business Management Journal, 17(1), 1-19. doi:10.30813/bmj.

Yuliana, Vinsia dan Santoso, Sugeng (2021). Re-engineering and Technology Development on Reference Sample of Business Process (Case Study on Health Laboratory Service Company). Jurnal Ilmiah Manajemen dan Bisnis, 7(2). Page 212-222. 